\title{
SISTEM INFORMASI PENGOLAHAN DATA KELAPA SAWIT BERBASIS CLIENT-SERVER
}

\author{
Sunardi' ${ }^{1}$ Sofiansyah Fadli² \\ 1,Teknik Informatika, Universitas Atma Jaya Yogyakarta, 2,Teknik Informatika, STMIK Lombok \\ 1,Janti, Caturtunggal, Kec. Depok, Kabupaten Sleman, Daerah Istimewa Yogyakarta 55281, \\ 2,Jln. Basuki Rahmat No.105 Praya Lombok Tengah 83511 \\ ${ }^{1}$ soenardhi.75@gmail.com, ${ }^{2}$ sofiansyah182@gmail.com
}

\begin{abstract}
Currently the development of information technology increasingly widespread, this is in line with the development of computers that are increasingly rapidly. Various technologies can now be created so as to facilitate all human activity. Sophistication of information technology has now become one of the requirements that must be met in order to keep up with technology. Technology and information that can not be separated from one another. But now there are many companies that have not implemented such a system because they various things. One problem is the lack of knowledge about the company's computer system, resulting in the company using the manual method, for example in the process of data processing. In this case PT. Citra Riau Sarana as one of the companies engaged in plantations, especially in the buying and selling palm oil CPO (Crude Palm Oil), which is still occurring problems in the data processing is still manual, so experiencing difficulties and frequent errors in data processing. The method used is the method of data collection by observation, interviews, library research, design models described using data flow diagrams (DAD) and entity relationship diagram (ERD). This application was built using Delphi 7 and SQL Server 2005.

Applications that use the Desktop and Client-Server based, hoped to use this application the Company may reduce the level of unwanted errors and speed up data processing.
\end{abstract}

Keywords : Client-Server, CPO, Data Processing, Information Systems, SDLC

\begin{abstract}
Abstrak
Dewasa ini perkembangan teknologi informasi semakin meluas, hal ini sejalan dengan perkembangan komputer yang semakin hari semakin pesat. Berbagai teknologi kini telah dapat diciptakan sehingga dapat memudahkan segala aktivitas manusia. Kecangihan teknologi informasi kini telah menjadi salah satu kebutuhan yang harus dipenuhi agar dapat mengikuti perkembangan teknologi. Teknologi dan informasi yang tidak dapat dipisahkan satu sama lain. Namun saat ini masih banyak perusahaan yang belum menerapkan sistem tersebut kerena berbagai hal. Salah satu kendalanya adalah kurangnya pengetahuan perusahaan tentang sistem komputerisasi sehingga mengakibatkan perusahaan mengunakan cara manual misalnya dalam melakukakan proses pegolahan data. Dalam hal ini PT. Citra Riau Sarana sebagai salah satu perusahaan yang bergerak di bidang perkebunan khususnya dalam pembelian kelapa sawit dan menjual CPO (Crude Palm Oil), dimana masih terjadi permasalahan pada proses pengolahan data yang masih manual, sehingga mengalami kesulitan dan sering terjadi kesalahan dalam pengolahan data. Metode yang digunakan adalah metode pengumpulan data dengan cara observasi, wawancara, studi pustaka, desain model digambarkan dengan menggunakan diagram aliran data (DAD) dan entity relationship diagram (ERD). Aplikasi ini dibangun menggunakan Delphi 7 dan SQL Server 2005. Aplikasi yang digunakan berbasis Desktop dan Client-Server, Diharapkan dengan menggunakan aplikasi ini Perusahaan tersebut dapat mengurangi tingkat kesalahan yang tidak dikehendaki dan mempercepat proses pengolahan data.
\end{abstract}

Kata kunci : Client-Server, Pengolahan Data, Sistem Informasi, SDLC 


\section{Pendahuluan [Cambria10, bold]}

Kemajuan teknologi informasi saat ini berkembang semakin cepat tanpa mengenal waktu dan menjadi kebutuhan yang sangat penting bagi semua kalangan baik dikalangan negeri maupun swasta. Berbagai aplikasi sistem informasi memungkinkan pemrosesan data dan laporan secara cepat dan akurat. Ragam penggunaan teknologi mengakibatkan hampir seluruh bidang kehidupan berubah menjadi komputerisasi, salah satunya pada instansi perusahaan dibidang perkebunan.

PT. Citra Riau Sarana yang beralamat di Jln. Soekarno Hatta Teluk Kuantan Riau, merupakan pabrik perusahaan yang bergerak dibidang perkebunan yang mengolah buah kelapa sawit menjadi minyak setengah jadi atau sering disebut CPO (Crude Palm Oil). Demi meningkatkan kinerja yang lebih baik pihak perusahaan berusaha memperbaiki sistem informasinya terutama dalam proses pembelian kelapa sawit dan penjualan CPO. Dengan tujuan mengurangi terjadinya kesalahan dengan sistem pengolahan data yang baik.

Dimana proses pengolahan data perusahaan masih bersifat manual karena hanya dilakukan dengan cara dicatat dalam buku biasa, sehingga memungkinkan terjadinya suatu kesalahan dan data yang ada akan mudah hilang ataupun rusak. Selain itu, dari proses pencariaan data pun mengalami kesulitan, sehingga membutuhkan waktu yang lama dalam pengolahan datanya.

Berkaitan dengan latar belakang masalah tersebut, untuk memperbaiki suatu sistem informasi guna mencapai hal-shal yang menyangkut peningkatan kinerja dan mempermudah dalam mendapatkan informasi. Maka penulis tertarik untuk membahas, memahami dan mencoba lebih lanjut, Untuk melakukan penelitian dalam sebuah perencanaan Tugas Akhir dengan judul "Sistem Pengolahan Data Kelapa Sawit Berbasis Client-Server" Studi Kasus Pada PT. Citra Riau Sarana, Teluk Kuantan Riau, Sistem aplikasi komputer ini berbasis desktop dengan menggunakan bahasa pemrograman Borland Delphi 7.0 sebagai aplikasinya dan Microsoft SQL Server 2005 sebagai databasenya. Dengan berbasis ClientServer maka aplikasi yang dibangun bisa diinstall lebih dari satu komputer dengan data yang sama, hal ini dapat memudahkan petugas dalam hal penginputan data maupun pembuatan laporan.

Sistem komputerisasi yang penulis bangun adalah untuk membantu meningkatkan kinerja perusahaan dalam melakukan penjualan CPO ke perusahaan lain untuk diproses menjadi barang jadi, sehingga diharapkan sistem yang dihasilkan akan lebih baik, cepat dan akurat. Selain itu juga akan mempermudah petugas dalam melakukan transaksi pembelian kelapa sawit dan pembuatan laporan. Adapun form yang akan dibuat dalam aplikasi ini adalah penginputan data kelapa sawit, data pemasok, data pelanggan, data transaksi pembelian kelapa sawit dan data transaksi penjualan $\mathrm{CPO}$.

\section{Tinjuan Pustaka}

\section{A. Penelitian Terkait}

Penelitian sebelumnya merupakan sumber referensi sekaligus acuan penulis untuk membangun Sistem Pengolahan Data Kelapa Sawit, karya ilmiah tersebut dilakukan oleh: Pasaribu, (2009) dalam jurnal penelitiannya dengan judul "Sistem Informasi Pengolahan Data Penjualan Kelapa Sawit pada Pusat Penelitian Pemantang Siantar Berbasis Web".

Pada penelitian tersebut menggunakan metode penelitian deskriptif dimana pengolahan datanya menggunakan bahasa pemrograman PHP dan MYSQL sebagai databasenya. Permasalahan yang diuraikan dalam jurnal penelitian yang telah dilakukan adalah dalam pengolahan data transaksi penjualan masih bersifat manual sehingga banyak terjadi kesalahan dalam proses pembuatan laporannya, sehingga peneliti memberikan solusi untuk memecah permasalahan yang terjadi adalah memperbaiki prosedur yang sudah ada, sehingga sistem tidak bersifat manual lagi, kesalahan yang sering terjadi dalam sistem tersebut tidak terulang kembali.

Siburian, (2010) dengan penelitiannya yang berjudul "Perancangan Sistem Basisdata Kelapa sawit Berbasis Client-Server" studi kasus PT. Sawit Riau Makmur, penelitiannya menggunakan Borland Delphi 7.0 dan MYSQL sebagai databasenya. Permasalahan telah diuraikan dalam jurnal penelitian yang dilakukan adalah tidak adanya prosedur sistem yang teratur. Jurnal penelitian tersebut bertujuan untuk membuat dan merancang sistem basis data, membuat sistem yang saling terhubung, dan penyimpanan data server.

\section{B. Data Flow Diagram (DFD)}

Merupakan diagram yang menggunakan notasi-notasi untuk menggambarkan arus dari data sistem. DFD sering digunakan untuk menggambarkan suatu sitem yang telah ada atau 
sistem baru yang akan dikembangkan secara logika tanpa mempertimbangkan lingkungan fisik dimana data tersebut mengalir. Diagram Arus Data (data flow diagram) adalah gambaran grafis yang memperlihatkan aliran data dari sumbernya. Dalam objek kemudian melewati suatu proses yang menstransformasinya ke tujuan yang lain, yang ada pada objek lain (Fatta, 2007).

\section{Pengertian Sistem}

Sistem pada dasarnya adalah sekelompok unsur yang erat hubungannya satu dengan yang lain, yang berfungsi bersama-sama untuk mencapai tujuan tertentu. Dari definisi ini dapat dirinci lebih lanjut pengertian sistem secara umum (Sutabri, 1998), yaitu sebagai berikut:

1. Setiap sistem terdiri dari unsur-unsur, unsurunsur suatu sistem terdiri dari subsistem yang lebih kecil, yang terdiri pula dari kelompok unsur yang membentuk subsistem tersebut.

2. Unsur-unsur tersebut merupakan bagian terpadau sistem yang bersangkutan. Unsurunsur sistem berhubungan erat satu dengan yang lain dan sifat serta kerja sama antarunsur sistem tersebut mempunyai bentuk tertentu.

3. Unsur sistem tersebut bekerja sama untuk mencapai tujuan sistem.

4. Suatu sistem merupakan bagian dari sistem yang lain yang lebih besar.

\section{Entity Relationship Diagram (ERD)}

Merupakan gambar atau diagram yang menunjukan informasi dibuat, disimpan, dan digunakan dalam sistem bisnis, dimana entitas biasanya menggambarkan jenis informasi yang sama yang digunakan untuk menghubungkan antar entitas yang sekaligus menunjukan hubungan antar data (Fatta, 2007).

\section{E. Diagram Context}

Diagram Context (top level) adalah bagian dari data flow diagram yang berfungsi memetakan model lingkungan yang dipresentasikan dengan lingkaran tunggal yang mewakili keseluruhan sistem (Fatta, 2007).

\section{F. Normalisasi}

Normalisasi merupakan salah satu cara pendekatan atau teknik yang digunakan dalam mengembangun desain lojik basis data relation dengan menerapkan sejumlah aturan dan criteria. Tujuan dari normalisasi adalah untuk menghasilkan struktur tabel yang normal dan baik. Syarat paling penting pada penyusunan sistem basis data adalah relasi dalam basis data harus normal. Oleh karena itu perlu dilakukan normalisasi terhadap basis data yang akan dibangun. Adapun syarat sebuah data dikatakan normal apabila telah sampai pada bentuk normal ketiga (Fatta, 2007).

\section{Metodologi Penelitian}

\subsection{Teknik Pengumpulan Data}

Metodologi penelitian ini bertujuan untuk mendukung dalam memperoleh informasi yang dibutuhkan dalam rangka mencapai tujuan penelitian. Teknik pengumpulan data yang benar akan menghasilkan hasil perbandingan dari apa yang diteliti sebelumnya. Untuk mendapatkan data yang lengkap dan akurat, pada tahap analisis dilakukan metode pengambilan data yang meliputi:

1. Metode Pengamatan (Observasi)

Pengumpulan data yang dilakukan dengan mengadakan pengamatan dan pencatatan dengan meninjau langsung bagaimana tata kerja petugas pada PT. Citra Riau Sarana dengan tujuan mencari dan mengumpulkan data yang diperlukan sehingga akan diperoleh data yang sistematis dan sesuai dengan tujuan penelitian.

\section{Metode Studi Pustaka}

Pengumpulan data yang penulis lakukan yaitu dengan cara mempelajari dan mengumpulkan sumber pustaka yang diperoleh dari berbagai buku-buku yang berkaitan dengan judul penelitian, hasil penelitian, skripsi, dan media lain sebagai referensi penulis dalam melakukan penelitian.

3. Metode Interview Atau Wawancara

Metode pengumpulan data dilakukan dengan mengajukan pertanyaan-pertanyaan atau wawancara langsung dengan para pelaku yang terdapat dalam sistem. Dalam kasus ini pihak yang di wawancara adalah petugas yang mengelola bagian proses administrasi dan transaksi pada PT. Citra Riau Sarana.

\section{Metode Dokumentasi}

Teknik pengumpulan data dengan cara mengumpulkan data yang diperoleh dari dokumen yang ada atau catatan - catatan yang tersimpan, baik itu berupa catatan transkrip, buku tamu, agenda, laporan, dimana penulis mempelajari dan mereview data pada dokumen milik perusahaan yang berhubungan dengan sistem pengolahan data kelapa sawit PT. Citra Riau Sarana dimana dokumen yang telah diperoleh kemudian dianalisis, dibandingkan dan dipadukan sehingga membentuk satu hasil kajian yang sistematis.

\subsection{Model Perancangan}

Sistem pendukung keputusan untuk penerima beasiswa ini adalah SDLC (Systems 
Development Life Cycle). Metode pengembangan terstruktur dengan pendekatan siklus hidup pengembangan sistem atau tahapan utama siklus hidup pengembangan sistem. Pengembangan sistem dapat berarti menyusun suatu sistem yang baru untuk menggantikan sistem yang lama secara keseluruhan atau memperbaiki sistem yang telah ada. Adapun tahapan-tahapan SDLC antara lain:

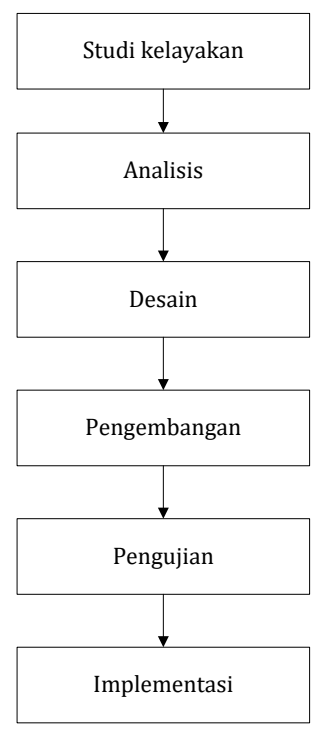

Gambar 3.1 Model Perancangan SDLC

a. Studi kelayakan. Studi kelayakan bertujuan untuk mengetahui apakah sistem baru tersebut realistis dalam masalah pembiayaan, waktu, serta perbedaan dengan sistem yang ada sekarang. Biasanya dalam tahap studi kelayakan ini diputuskan untuk mengupdate sistem yang ada atau menggantinya dengan sistem yang baru.

b. Analisis. Pengguna dan software developer bekerjasama mengumpulkan, mempelajari, dan merumuskan kebutuhan-kebutuhan bisnis.

c. Desain. Pembuatan blueprint sistem dan penyesuaian dengan arsitektur telekomunikasi, hardware, dan software untuk pengembangan lebih lanjut, serta membuat model sistem menciptakan model graphical user interface, database, dan lain-lain.

d. Pengembangan. Pada tahapan ini, barulah para programmer melakukan coding untuk menerapkan desain ke dalam sistem yang sesungguhnya, membuat program, dan menyiapkan database.

e. Pengujian. Setelah sistem berhasil dikembangkan, langkah selanjutnya adalah pengujian untuk melihat apakah sistem telah sesuai dengan harapan dan kebutuhan pengguna.

f. Implementasi. Tahap ini, software yang telah diuji siap diimplementasikan ke dalam sistem pengguna. Pembuatan user guide dan pelatihan juga dilakukan.

\section{Hasil dan Pembahasan}

1. Tampilan Data Login

Ketika program dijalankan, maka akan tampil form login yang harus diisi untuk dapat masuk ke tampilan program yang lain

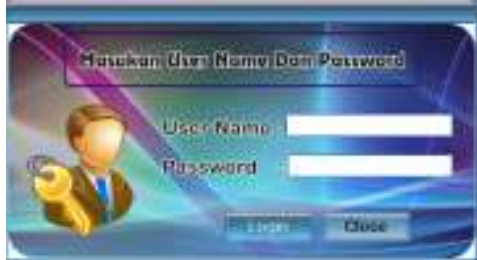

Gambar 4.1 Halaman Login

2. Tampilan Halaman Utama

Pada menu utama ini terdapat menu toolbar untuk memanggil form menu yang tersedia pada aplikasi. Tampilan menu utama sebagai berikut:

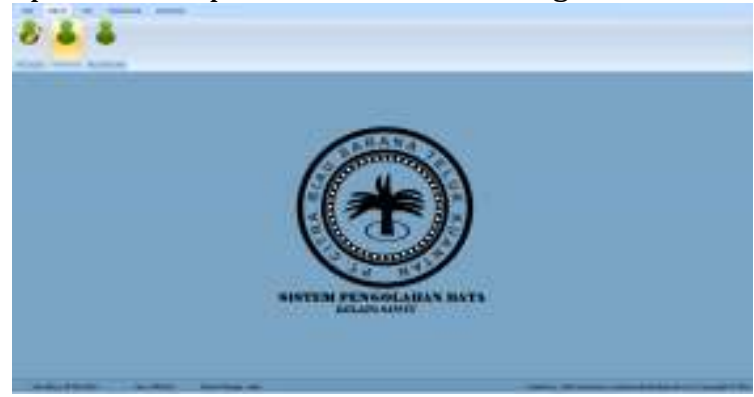

Gambar 4.2 Halaman Utama

3. Tampilan Form Data Pemasok Halaman ini berfungsi untuk mengisi data pemasok.

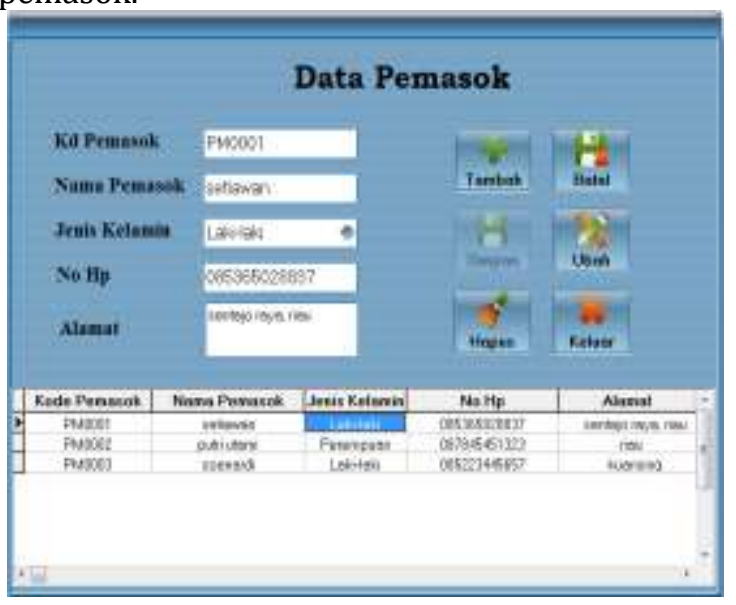

Gambar 4.3 Halaman Data Pemasok 
4. Tampilan Laporan Pemasok

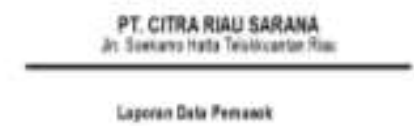

\begin{tabular}{|c|c|c|c|c|c|}
\hline in & Kode Pennes & hara/nenea & a r Kam & hrovio & Laval \\
\hline 1 & peosent & Inawn & taile & atrescent & latsep aca. ra \\
\hline 2 & pwoan & Maviami & Nemain. & 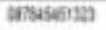 & $=$ \\
\hline 3 & Proon & $w$ & Give & atcousen? & haney \\
\hline
\end{tabular}

Gambar 4.4 Halaman Laporan Pemasok

5. Tampilan Form Data Pelanggan

Halaman ini berfungsi untuk mengisi data pelanggan.

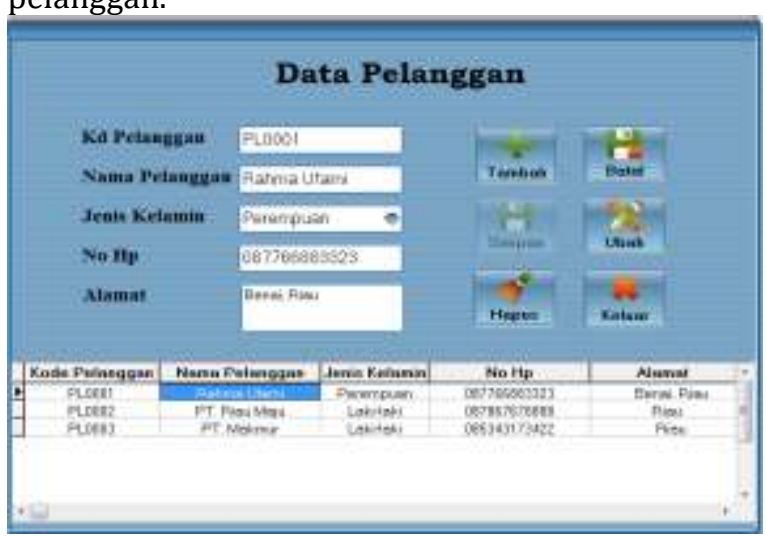

Gambar 4.5 Halaman Data Pelanggan

6. Tampilan Laporan Pelanggan

\begin{tabular}{|c|c|c|c|c|c|}
\hline \multicolumn{6}{|c|}{ 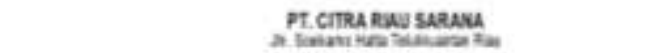 } \\
\hline \multicolumn{6}{|c|}{ 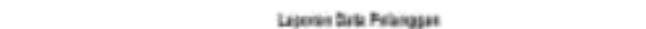 } \\
\hline at & katraup & Senteryes & $m 06$ & Nonas: & sene \\
\hline 1 & nutei & Enavis & Anmtar & cervenests & tex an: \\
\hline 2 & naed & Thas we & Len & memat & aw \\
\hline 1 & nued & nt went & not & masoug & na \\
\hline
\end{tabular}

Gambar 4.6 Halaman Laporan Pelanggan

7. Tampilan Form Transaksi Pembelian

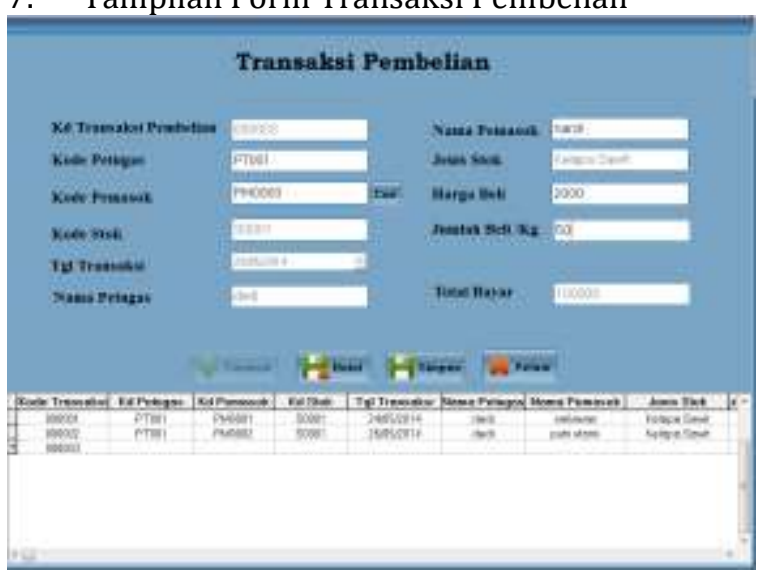

Gambar 4.7 Halaman Transaksi Pembelian
8. Laporan Transaksi Pembelian

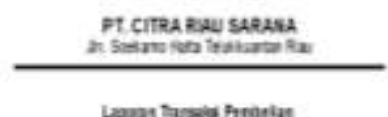

\begin{tabular}{|c|c|c|c|c|c|c|c|}
\hline 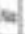 & stives: & ytronew & Satufenes & $\cos x$ & ands & kepse & laviese. \\
\hline 1 & सका & josmu & Inter & Geatent & an 5 & to:2x & $62 \pi x$ \\
\hline 2 & $x=$ & $2015 x / 4$ & anam & exalane & 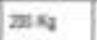 & 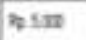 & tour: \\
\hline y) & Ind & 20584 & 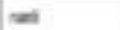 & cenested & 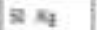 & ค:2II & 요료 \\
\hline
\end{tabular}

Gambar 4.8 Laporan Transaksi Pembelian

9. Tampilan Form Transaksi Penjualan

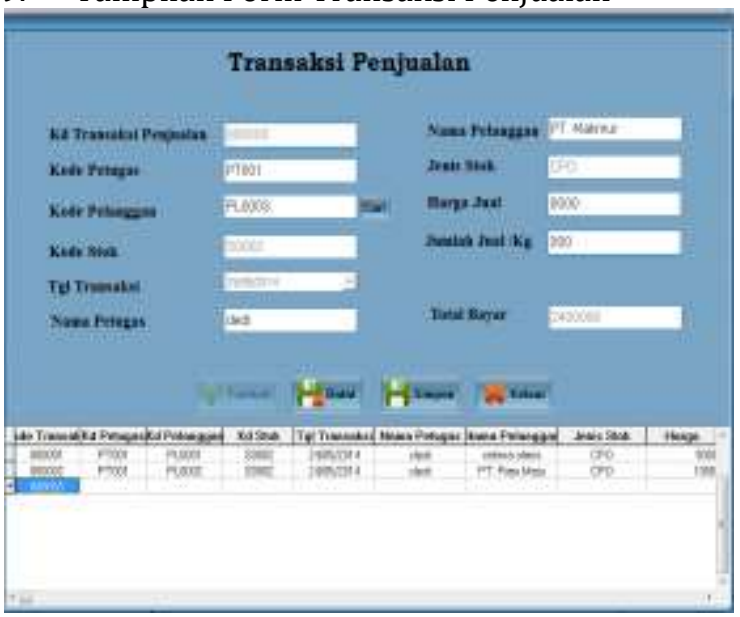

Gambar 4.9 Halaman Transaksi Penjualan

10. Laporan Transaksi Penjualan

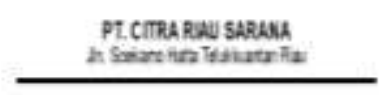

Lapan laseis feialan

\begin{tabular}{|c|c|c|c|c|c|c|c|}
\hline & Glasas: & Py Truas: & Lan Feagr & $2 x \operatorname{sa}$ & aniada & kapiala & fors les \\
\hline 1 & Iex: & $3 \sin 4$ & arvatri & p2 & \& $\mathrm{K}_{9}$ & क्षिया & 9170200 \\
\hline 2 & $20 x$ & zassod & Fi:kalle & 100 & es $\times 9$ & 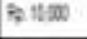 & 7. \\
\hline 1 & Iat) & 25254 & it Vaine & (52) & 308 & At:10 & Aptaner \\
\hline
\end{tabular}

Gambar 4.10 Laporan Transaksi Penjualan

Laporan Data Stok

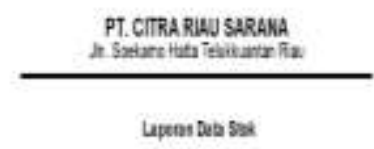

\begin{tabular}{|c|c|c|c|}
\hline $\mathrm{se}$ & Eon 52 & ans $5 x$ & $\operatorname{Irih} 5 a$ \\
\hline 1 & 50001 & Kasa Sare & toall $x_{i}$ \\
\hline 2 & 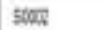 & 000 & tho $\mathrm{Ng}$ \\
\hline
\end{tabular}

Gambar 4.11 Laporan Data Stok 


\section{Kesimpulan dan saran}

\subsection{Kesimpulan}

Berdasarkan pengamatan dan penelitian yang dilakukan, maka diperoleh beberapa kesimpulan yaitu dengan adanya program aplikasi terkompuerisasi ini, dapat membantu permasalahan proses pengolahan data pada perusahaan PT. Citra Riau Sarana yang masih menggunakan cara manual untuk melakukan pecatatan data transaksi dan pembuatan laporannya. Sistem ini akan memudahkan bagi petugas dibagian administrasi untuk mengakses data transaksi penjualan, data transaksi pembelian, data pelanggan, data pemasok, data petugas dan data stok, sehingga dapat meminimalisir kesalahan atau kekeliruan yang selama ini sering terjadi pada PT. Citra Riau Sarana.

\subsection{Saran}

Saran yang dapat disampaikan oleh penulis adalah agar penelitian berikutnya bisa mengembangkan sistem ini lebih baik lagi, sehingga kekurangan yang ada bisa dilengkap atau diperbaiki. Saran yang dapat digunakan sebagai bahan pertimbangannya adalah hasil perhitungan laporan sebaiknya dilengkapi dengan menggunakan grafik, agar lebih memperlihat perbandingan yang terjadi.

\section{Daftar Pustaka:}

\section{Pustaka Buku}

(1) Al Fatta, H. "Analisis Dan Perancangan Sistem Informasi." (2007): Andi. Yogyakarta.

(2) Fadli, Sofiansyah. "Model Rapid Application Development Dalam Pengembangan Sistem Reservasi Dan Penyewaan Kamar Hotel." JIRE: Jurnal Informatika \& Rekayasa Elektronika. 1.1 (2018): 57-64.

(3) Hodia, Maelani, and Khairul Imtihan. "Perancangan Sistem Informasi Praktek Klinik Kebidanan (PKK) Pada Prodi DIII Kebidanan Stikes Qamarul Huda." IJNSIndonesian Journal on Networking and Security 6.3 (2017).
(4) Imtihan, Khairul, Rabiatul Hadawiyah, and Hasyim Asyari-STMIK Lombok. "Sistem Informasi Penggajian Guru Honorer Menggunakan Konsep Agile Software Development dengan Metodologi Extreme Programming (XP) pada SMK Bangun Bangsa." IJNS-Indonesian Journal on Networking and Security 7.2 (2018).

(5) Khairul Imtihan. "Perencanaan Strategi Sistem Informasi Pendidikan Pada Sekolah Tinggi Manajemen Informatika dan Komputer (STMIK) Lombok." Bianglala Informatika 3.2 (2015).

(6) Laudon, Kenneth C. dan Jane P. Laudon. "Sistem Informasi Manajemen." (2007): Edisi ke-10. Terjemahan Chriswan Sungkono dan Machmudin Eka P. Salemba, Jakarta.

(7) Mulyadi. "Sistem Akuntansi Edisi Enam." (2009): Salemba, Jakarta.

(8) Pasaribu, Elvira. "Sistem Informasi Pengolahan Data Penjualan Kelapa Sawit pada Pusat Penelitian Pemantang Siantar Berbasis Web," (2009): Warta Pusat Penelitian Kelapa Sawit, Sumatera Utara.

(9) Sunardi., Fadli, Sofiansyah. "Identifikasi Masalah Penerapan Metode Agile (Scrum) Pada Pengembangan Perangkat Lunak Di Perguruan Tinggi." MISI (Jurnal Manajemen Informatika dan Sistem Informasi) 2.1 (2018).

(10) Sutabri, Tata. "Sistem Informasi Manajemen." (1998): Andi. Yogyakarta.

(11) Shalahuddin, M dan Rosa A.S. "Modul Pembelajaran Rekayasa Perangkat Lunak (Terstruktur dan Berorientasi Objek)," (2011): Modula, Bandung.

(12) Siburian, Norma. "Perancangan Sistem Basisdata Kelapa sawit Berbasis ClientServer," (2010): Warta Pusat Penelitian Kelapa Sawit,Sumatera Utara.

(13) Sutabri, Tata. "Sistem Informasi Manajemen," (2005): Andi, Yogyakarta.

(14) Susanto, Azhar. "Sistem Informasi Manajemen Konsep dan Pengembangannya," (2010): Lingga Jaya, Bandung. 